\title{
Rapid quantification of cellular proliferation and migration using Image $J$
}

$\overline{\text { C Venter }^{1} \text { \& CU Niesler }}{ }^{*, 1}$

\section{ABSTRACT}

Cellular proliferation and migration are crucial during development, regeneration and disease. Methods to quantify these processes are available; however, many are time consuming and require specialized equipment and costly reagents. Simple cell counts (proliferation analysis) and the scratch assay (migration analysis) are favorable methods due to their simplicity and cost-effectiveness; however, they rely on subjective and laborintensive manual analysis, resulting in low throughput. We have developed optimized protocols to rapidly and accurately quantify adherent cell number and wound area using ImageJ, an open-source image processing program. Notably, these adaptable protocols facilitate quantification with significantly greater accuracy than manual identification.

\section{METHOD SUMMARY}

Optimized automated methods to rapidly quantify proliferation and migration of adherent cells using ImageJ are presented. These methods support high-throughput and deliver enhanced accuracy when compared to manual analysis.

\section{KEYWORDS}

adherent cell counts - ImageJ • migration $\cdot$ myoblast $\cdot$ scratch assay - proliferation

Discipline of Biochemistry, School of Life Sciences, University of KwaZuluNatal, Private Bag X01, Scottsville 3209, South Africa; *Author for correspondence: niesler@ukzn.ac.za

BioTechniques 66: 99-102 (February 2019) 10.2144/btn-2018-0132
Cellular proliferation and migration are important processes during tissue development, repair and disease. Following skeletal muscle injury, proliferation and migration of activated muscle stem cells (myoblasts) is crucial to ensure that sufficient progenitor cells reach the wound site and facilitate repair [1]. Myoblast proliferation and migration are regulated by signalling molecules released from the extracellular matrix and resident/infiltrating cells such as macrophages and fibroblasts [2]. Proliferation can be quantified by measuring changes in DNA (via BrdU, ${ }^{3} \mathrm{H}$-Thymidine), metabolism (via MTT), proliferation-specific proteins (e.g., Ki-67) or simple cell counts (e.g., hemocytometer, TC20"') [3-7]. Migration can be assessed by determining the number of cells that move across a microporous membrane (transwell migration assay) or by measuring the surface area that cells occupy over time after creating a 'cell-free' area (scratch assay) [8-10]. Of these, cell counts and the scratch assay are favorable methods due to their cost-effective and simple nature, with fewer steps and a reduced need for specialized equipment.

ImageJ, a popular opensource image processing program, has previously been used to manually count cells (selecting and tallying individual cells) and assess wound closure (tracing the wound perimeter and calculating percentage closure) [11-13]. These manual approaches are laborious and time-consuming, whereas automated image analyses would facilitate a higher throughput and greater objectivity. In the current study, we utilized the image processing capabilities of ImageJ to develop an optimized batch processing macro for rapid and accurate identification and quantification of adherent cell number and wound area from images captured using a brightfield phase contrast microscope. We demonstrate that these protocols are easier, faster and more objective than alternative methods.
Murine $\mathrm{C} 2 \mathrm{C} 12$ myoblasts (ATCC, cat. CRL-1772', USA) were cultured at $37^{\circ} \mathrm{C}$ and $5 \% \mathrm{CO}_{2}$ and maintained in growth media (GM) containing Dulbecco's Modified Eagle's Medium (Sigma, cat. D5648, USA) supplemented with $10 \%(\mathrm{v} / \mathrm{v})$ Fetal Bovine Serum (Gibco, cat. 10500, USA), 2\% (v/v) penicillinstreptomycin (LONZA, cat. DE17-602E, Switzerland). Media was changed every $48 \mathrm{~h}$. Results were analyzed using either a paired, two-tailed Student's T-test (for comparison between methods at a single cell number or timepoint; Figure 1B \& 2 C) or one-way ANOVA (for cell number changes within a method; Figure $1 C$ ), and values of $p<0.05$ considered statistically significant. All data were represented as mean \pm SEM.

For proliferation analysis, myoblasts (5, $10,20,40,60,80$ and $100 \times 10^{3}$ cells) were cultured in GM $(500 \mu \mathrm{l})$ in a 24 -well plate for $3 \mathrm{~h}$ to promote adherence. Media was then removed, and cells stained with $0.2 \%$ (w/v) crystal violet (Sigma, cat. C-3886) in methanol (Sigma, cat. 24229) for $15 \mathrm{~min}$; excess stain was subsequently removed by water submergence and the plate left to air dry. Cells were visualized using an Olympus CKX41 microscope (4x objective lens) and images captured (three fields of view per replicate; three replicates) with a Motic 3.0 megapixel camera. Cell number was assessed and compared using three methods: manual cell identification, automated cell identification and the spectrophotometric (crystal violet) assay.

For manual identification, captured images were converted to grayscale in ImageJ (Image $\rightarrow$ Type $\rightarrow$ 8-bit) (Figure 1Ai), the cells were manually marked out with a red pencil dot (size: 4 px) in Microsoft Paint (Figure Aii), the dots were then automatically identified (Image $\rightarrow$ Adjust $\rightarrow$ Color Threshold (Hue 225 to 255; Dark Background: True)) and counted (Analyze $\rightarrow$ Analyze Particles) using ImageJ. For automated identification, the images were converted to grayscale, image noise removed (Process $\rightarrow$ Noise $\rightarrow$ Despeckle), brightness and 


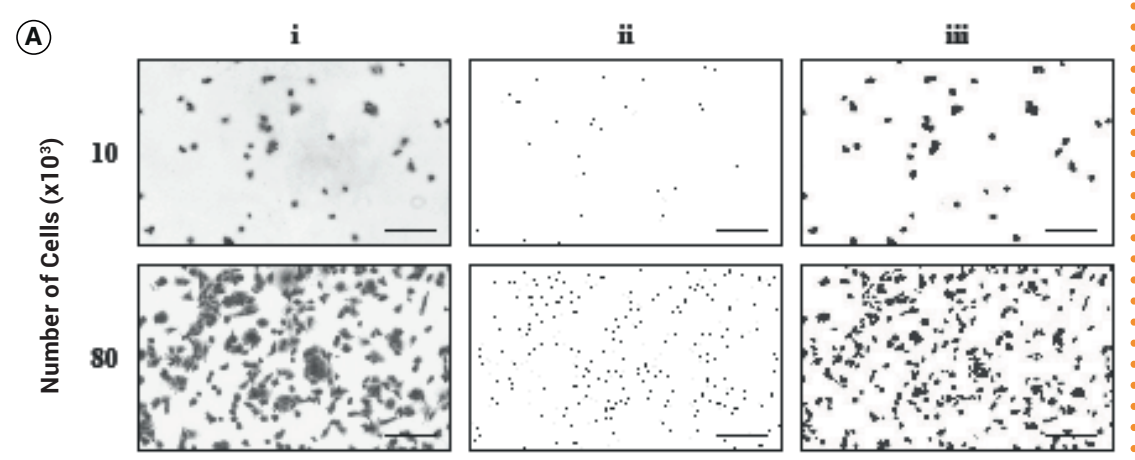

(B)

Manual a Automated

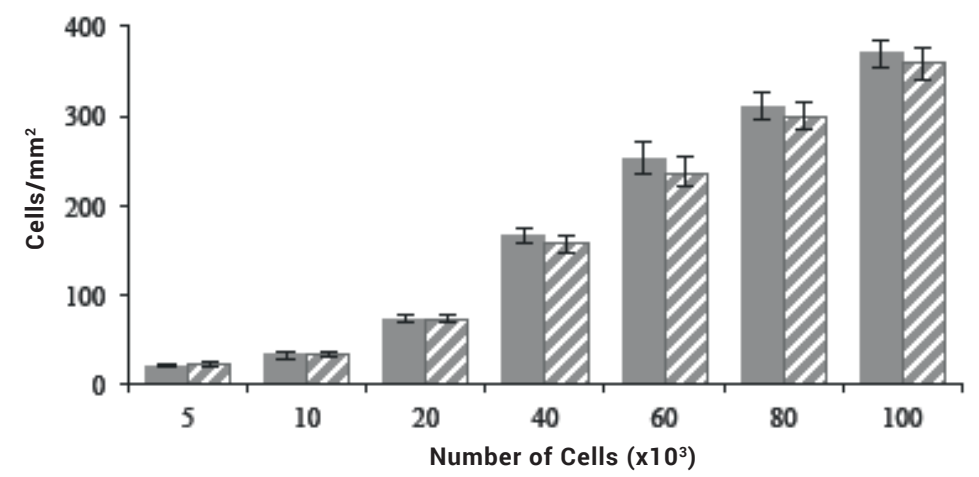

(C)

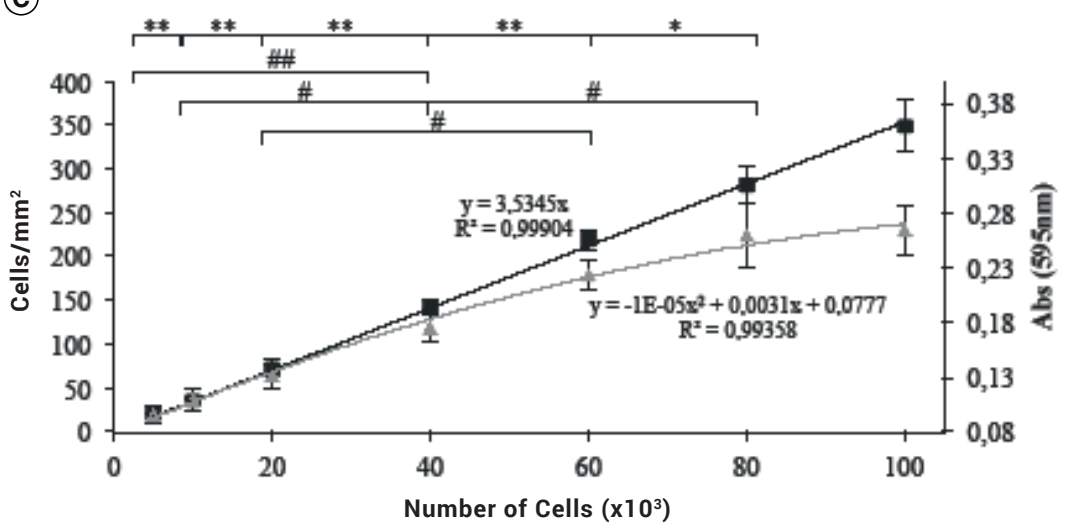

Figure 1. Quantification of cell number: a comparison of manual, automated (ImageJ) and spectrophotometric identification methods. (A) $\mathrm{C} 2 \mathrm{C} 12$ myoblasts $\left(10 \times 10^{3}\right.$ and $80 \times 10^{3}$ are shown) were stained with crystal violet and captured with an Olympus CKX41 microscope coupled to a Motic 3.0 megapixel camera: (i) Brightfield images prior to processing, (ii) cells manually marked in Microsoft Paint and subsequently counted, (iii) cells automatically identified using the optimized Image J macro and subsequently counted. Scale bar $=200 \mu \mathrm{m}$. (B) Standard curve of cell density (cells/ $\mathrm{mm}^{2}$ ) following application of the manual versus the automated ImageJ analysis. (C) Standard curve of cell density (cells $/ \mathrm{mm}^{2}$ ) following application of automated Image J analysis versus spectrophotometry.

${ }^{*} \mathrm{p}<0.05$ and ${ }^{* *} \mathrm{p}<0.005$ for automated Image J analysis; $\# \mathrm{p}<0.05$ and \#\#p $<0.005$ for spectrophotometric analysis; $n=4-9$.

$\checkmark$ contrast adjusted (Image $\rightarrow$ Adjust $\rightarrow$ Brightness/Contrast: $\min =87 ; \max =167$ ), and a Phansalkar threshold (Image $\rightarrow$ Adjust $\rightarrow$ Auto Local Threshold: Phansalkar) and watershed (Process $\rightarrow$ Binary $\rightarrow$ Watershed) clustered cells from one another. The identified cells were finally counted using ImageJ. For spectrophotometric analysis, the crystal violet-stained cells were solubilized with $200 \mu$ l SDS (1\% w/v; Merck, cat. SAAR5823610EM, USA) for $1 \mathrm{~h}$; $100 \mu \mathrm{l}$ of the solution was then removed and added to a 96-well microplate [14]. The absorbance (595 nm) was read using the FLUOoptima micro 96-well plate reader.

For proliferation analysis, myoblasts were manually counted or identified and assessed using ImageJ. ImageJ could automatically identify cells at lower $\left(5 \times 10^{3}\right.$ cells $)$ and higher $\left(100 \times 10^{3}\right.$ cells $)$ numbers, despite the cells being clustered closely together; however, this is likely to become increasingly challenging as confluence is attained. No significant difference was found between automated (ImageJ) versus manual identification, confirming the accuracy of the automated method (Figure 1B). Manual cell identification was also a slow and laborious task compared to automated assessment. We then compared our automated cell number analysis with spectrophotometric analysis of crystal violet-stained cells; the latter assay is a simple, inexpensive method commonly used to quantify cell number (Figure 1C). The standard curve generated using the spectrophotometric assay yielded a polynomial line $\left(y=-1 E-05 x^{2}+0.0031 x\right.$ $\left.+0.0777 ; R^{2}=0.9936\right) ;$ as the number of plated cells increased, the absorbance (at $595 \mathrm{~nm}$ ) increased, but plateaued after $60 \times 10^{3}$ cells ( $65 \%$ confluence), possibly due to crystal violet saturation (Figure 1C). By contrast, the standard curve generated using the automated Image $J$ macro resulted in a straight line $\left(y=3.5345 x ; R^{2}=0.999\right)$, indicating a directly proportional relationship between the number of cells plated and the number calculated per $\mathrm{mm}^{2}$. In addition, each sequential increase in plated cell number was reflected as a significant increase in cell density when utilizing the automated counting method; this was not the case for the polynomial generated from crystal violet absorbance readings (Figure 1C). Therefore, ImageJ was sensitive enough to accurately detect both smaller changes in cell numbers and a wider range of cellular densities than spectrophotometric analysis of crystal violet-stained cells.

For migration analysis, myoblasts $\left(120 \times 10^{3}\right)$ were plated out in $\mathrm{GM}(1 \mathrm{ml})$ in 
a 12-well plate for $24 \mathrm{~h}$, before a scratch assay was performed as described by Goetsch et al. [15]. Briefly, the confluent monolayer of myoblasts was scratched with a sterile $200 \mu$ l loading tip to create a linear 'wound' devoid of cells. The cells were then washed twice with sterile PBS and fresh GM $(500 \mu \mathrm{l})$ was added. The cells were incubated for $7 \mathrm{~h}$ and images captured at $0,3,5$ and $7 \mathrm{~h}$ using the camera-attached microscope ( $4 \mathrm{x}$ objective lens; two fields of view per replicate, for two replicates). To measure wound area manually, the edges of the wound were traced using the Motic Images Plus 2.0 ML software [15]. To carry out automated wound area measurements, the captured image was converted to grayscale, the edges found (Process $\rightarrow$ Find Edges) and the image blurred (Process $\rightarrow$ Smooth) multiple times (x37). The Find Edges step highlighted sharp changes in intensity with a white outline so that when the image was blurred numerous times, these outlines blurred together; as a result, the areas containing cells were white whereas the wound area (devoid of cells) remained black. A MinError threshold was then applied (Image $\rightarrow$ Adjust $\rightarrow$ Auto Threshold: MinError) to automatically detect the wound area. If the wound area was not accurately selected, it could be manually thresholded (Image $\rightarrow$ Adjust $\rightarrow$ Threshold). Once the wound area was identified, it was then quantified (Analyze $\rightarrow$ Analyze Particles [size: 10,000 - infinity]).

The percentage wound closure was calculated and the results generated using the manual versus automated methods were compared (Figure 2). The use of ImageJ to detect wound edges revealed that, when compared with manual assessment, automated analysis was able to accurately define these edges (Figure 2A); in fact, the automated analysis seemed to define the wound edges more accurately than the manual method (Figure 2B). As a result, when the percentage wound closure was assessed, a significant difference between the manual $(12.13 \pm 0.98 \%)$ and automated $(7.54 \pm 0.76 \%)$ method was detected at $3 \mathrm{~h}$ post-wounding $(\mathrm{p}<0.05)$. This was attributed to the fact that Image $J$ could trace the outline of the wound more accurately than the researcher's manual attempt. This was particularly evident during early wound repair when the wound borders were not well defined and, therefore, harder to accurately

(A)
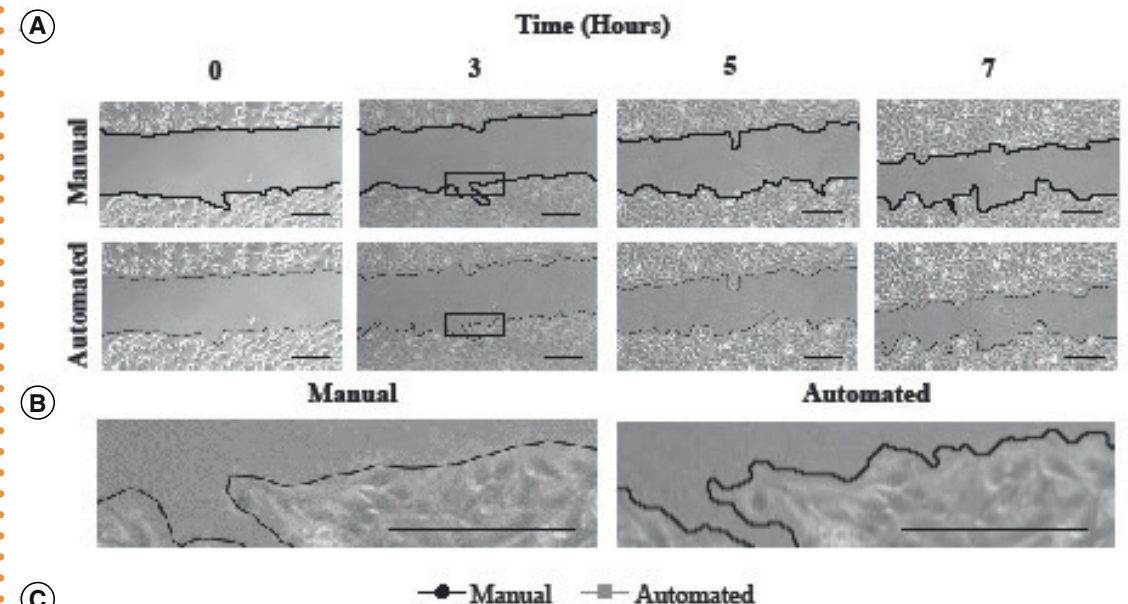

(C)

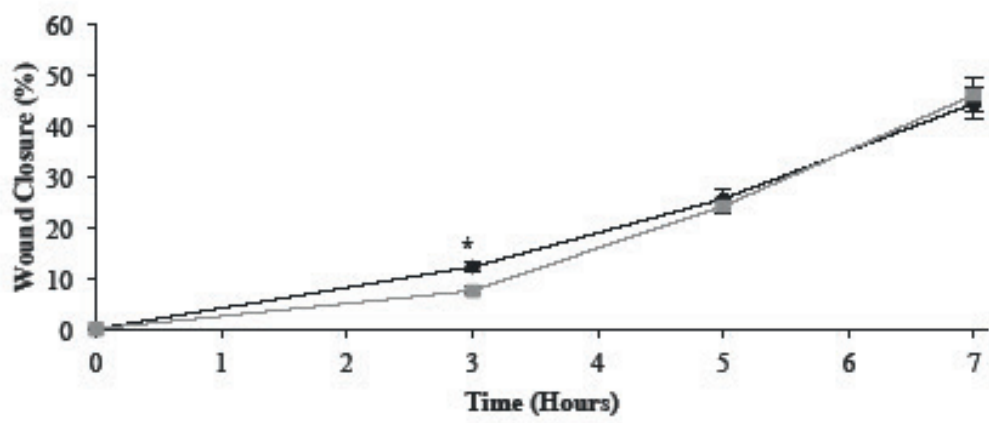

Figure 2. Quantification of wound area: a comparison of manual and automated (ImageJ) identification methods. (A) $\mathrm{C} 2 \mathrm{C} 12$ myoblasts $\left(120 \times 10^{3}\right)$ were scratched and images captured with an Olympus CKX41 microscope coupled to a Motic 3.0-megapixel camera $(0,3,5$ and $7 \mathrm{~h})$ : manual identification using Motic Images Plus 2.0 ML software to trace the wound edge and automated identification using ImageJ. (B) Zoomed-in images of wound edges following manual and automated identification at $3 \mathrm{~h}$. (C) Percentage wound closure (\%) at 3,5 and $7 \mathrm{~h}$ post-injury. ${ }^{*} \mathrm{p}<0.05 ; \mathrm{n}=16$. Scale bar $=200 \mu \mathrm{m}$.

trace. In addition to increased sensitivity and accuracy, the application of the Image J macro was less laborious and faster than manual analysis.

In summary, we have developed an optimized ImageJ-based automated method for rapid quantification of cell number and migration in vitro. Image J could automatically identify and accurately quantify cell numbers and wound area; in some cases, the results were superior to those generated via traditional manual or spectrophotometric methods. In addition, our macros generated data faster than previous manual methods. Although programs have previously been developed to count cells (e.g., CellC and CellCounter) or measure wound closure (e.g., TScratch) [16-19], they did not match the flexibility of ImageJ which, as a single program, can be extended to quantify cell number in tissue sections and suspension cultures or adapted to monitor important cellular processes [19]. Finally, the opensource nature of this software permits further optimization depending on user requirements, yielding a superior and versatile method compared with previous protocols.

\section{AUTHOR CONTRIBUTIONS}

CV: PhD postgraduate student responsible for the execution of the laboratory work, as well as compilation and revision of the manuscript. CUN: Senior author providing intellectual input and supervision to the student involved. This author also provided the funding for the project and contributed to revisions of multiple drafts of the article.

\section{FINANCIAL \& COMPETING INTERESTS DISCLOSURE}

The work was supported by the South African National Research Foundation 
- (Grant CPRR13091035184; 90502) and the University of KwaZulu-Natal. The authors have no other relevant affiliations or financial involvement with any organization or entity with a financial interest in or financial conflict with the subject matter or materials discussed in the manuscript apart from those disclosed.

No writing assistance was utilized in the production of this manuscript.

\section{OPEN ACCESS}

This work is licensed under the AttributionNonCommercial-NoDerivatives 4.0 Unported License. To view a copy of this license, visit http://creativecommons.org/licenses/ by-nc-nd/4.0/

\section{SUPPLEMENTARY DATA}

A supplementary protocol accompanies this paper. To view the supplementary data that accompany this paper please visit the journal website at: www.future-science. com/doi/suppl/10.2144/btn-2018-0132

\section{REFERENCES}

1. Mann CJ, Perdiguero E, Kharraz Y et al. Aberrant repair and fibrosis development in skeletal muscle. Skelet. Muscle 1(1), 21 (2011).

2. Bosurgi L, Manfredi AA, Rovere-Querini P. Macrophages in injured skeletal muscle: a perpetuum mobile causing and limiting fibrosis, prompting or restricting resolution and regeneration. Front. Immunol. 2, 62 (2011).

3. Hughes WL, Bond VP, Brecher $\mathrm{G}$ et al. Cellular proliferation in the mouse as revealed by the autoradiography
with tritiated thymidine. Proc. Natl Acad. Sci. USA 44(5), 476-483 (1958).

4. Gratzner HG. Monoclonal antibody to 5-bromo- and 5 -iododeoxyuridine: a new reagent for detection of DNA replication. Science 29(4571), 474-475 (1982).

5. Mosmann T. Rapid colorimetric assay for cellular growth and survival: Application to proliferation and cytotoxicity assays. J. Immunol. Meth. 65(1-2), 55-63 (1983).

6. Scholzen T, Gerdes J. The Ki-67 protein: from the known to the unknown. J. Cell. Physiol. 182(3), 311-322 (2000)

7. Boulton RA, Hodgson JF. Assessing cell proliferation: a methodological review. Clin. Sci. (Lond.) 88(2), 119-130 (1995).

8. Boyden S. The chemotactic effect of mictures of antibody and antigen on polymorphonuclear leucocytes. $J$. Exp. Med. 115(3), 453-466 (1962).

9. Lampugnani MG. Cell migration into a wounded area in vitro. Methods. Mol. Biol. 96, 177-182 (1999).

10. Hulkower KI, Herber RL. Cell migration and invasion assays as tools for drug discovery. Pharmaceutics 3(1) 107-124 (2011).

11. Schindelin J, Rueden CT, Hiner MC, Eliceiri KW. The Image J ecosystem: an open platform for biomedical image analysis. Mol. Reprod. Dev. 82(7-8), 518-529 (2015)

12. De Vos K. Cell counter. (2001). Available at: https:// imagej.nih.gov/ij/plugins/cell-counter.html (Accessed 6 September 2018).

13. Goetsch KP, Myburgh KH, Niesler CU. In vitro myoblast motility models: Investigating migration dynamics for the study of skeletal muscle repair. J. Muscle. Res. Cell. Motil. 34(5-6), 333-347 (2013).

14. Feoktistova $M$, Geserick P, Leverkus M. Crystal violet assay for determining viability of cultured cells. Cold. Spring. Harb. Protoc. 2016(4), pdb prot087379 (2016).

15. Goetsch KP, Niesler CU. Optimization of the scratch as say for in vitro skeletal muscle wound healing analysis. Anal. Biochem. 411(1), 158-160 (2011).

16. Selinummi J, Seppala J, Yli-Harja O, Puhakka JA. Software for quantification of labeled bacteria from digital microscope images by automated image analysis. Biotechniques 39(6), 859-863 (2005).

17. Li X, Yang H, Huang H, Zhu T. CELLCOUNTER: novel open-source software for counting cell migration and invasion in vitro. Biomed. Res. Int. 2014(2014), 6 (2014)

18. Geback T, Schultz MM, Kousmoutsakos P, Detmar M. TScratch: a novel and simple software tool for automated analysis of monolayer wound healing assays. Biotechniques 46(4), 265-274 (2009).

19. Abràmoff $M D$, Magalhães $P J$, Ram SJ. Image processing with ImageJ. J. Biophotonics 11(7), 36-42 (2004).

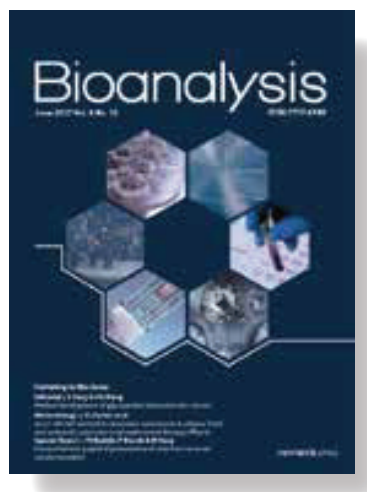

IMPACT FACTOR: 2.478 (2017)

In association with

80 Bioanalysis

www.bioanalysis-zone.com

\section{Bioanalysis}

ISSN: 1757-6180

Frequency per year: 24

\section{INDEXING}

MEDLINE/Index Medicus, EMBASE/Excerpta

Medica, Chemical Abstracts, BIOSIS Previews,

BIOSIS Reviews Reports and Meetings, Journal

Citation Reports/Science Edition, Science

Citation Index Expanded ${ }^{\text {TM }}\left(\right.$ SciSearch $\left.^{\circledR}\right)$, Scopus ${ }^{\circledR}$ 